\title{
Applied research on the improved Great Lakes Calculus Model used in the flood control scheduling of the middle and lower Yangtze river
}

\author{
Wan Fengming 1,2, a , Long Lihua ${ }^{3, b}$ \\ ${ }^{1}$ Wuhan University of Technology,Wuhan,China \\ 2 Hubei Business College,Wuhan,China \\ ${ }^{3}$ Hubei Water Resources Technical College,Wuhan,China \\ a564017119@qq.com, b1024025148@qq.com
}

Keywords: water control level ; flood routing; effect on flood control

Abstract: This paper used the measured data of water level and flow on the cross-sections of middle and lower Yangtze River during flood season (May-September) from 1981 to 2015. According to the evolution of the state of river course, flood and sediment, we calculated the flood routing with the improved Great Lakes flood routing model on the sections of Yichang to Shashi, Shashi to Chenglingji, Chenglingji to Hankou, Hankou to Hukou. And the results of the calculation was checked with the measured data in 1983, 1998,2002 and 2015, to verify the relationship between river and lake and the relevant parameters, and to provide detailed, accurate information for the subsequent models. The calculation results showed that the research was practical, and can be used as the basis of decision.

\section{Introduction}

The Yangtze Basin suffers frequent floods, particularly the economically-developed middle and lower reaches. Floods remain major worries of Chinese people until now.

Rainstorm strikes the upper reach of Yangtze River over the period from July to August and hits the middle and lower reaches during the period from May to July. The main stream of the middle and lower reaches drains floods of both the upper main stream and the middle and lower tributary streams. Floods often happen during the period from June to October. In addition, rainfall peaks in July and August, which leads to frequent floods of tributary streams.[1] In case the rainy season of the upper reach comes earlier and that of the middle and lower reaches comes later, Yangtze River will suffer flood and face serious flood prevention problems, particularly for the middle and lower reaches. In recent a few years, China and the communist party pay much attention to flood prevention of the Yangtze Basin. Although the Three Gorges Dam fundamentally improves the flood prevention ability of the middle and lower reaches of Yangtze River, it is necessary to grasp change rules of floods of Yangtze River for appropriate and comprehensive flood prevention planning. Based on de Saint-Venant system of equations, this paper integrates data of the rising water level into the water level-water flow curve of Chenglingji, Hankou, and Hukou[2]. ]By improving the calculation model of big lakes, this paper concludes the flood routing and diversion capacity in the middle and lower reaches. In addition, this paper verifies the calculation accuracy of the model by comparing calculation outcomes with on-site investigation data.

\section{Overall Geological and Hydrological Conditions}

The main stream of Yangtze River in the west of Yichang is the upper reach, covering a drainage area of about 1 million square meters. The section between Yichang and Hukou is the middle and lower reaches, covering a drainage area of about 0.68 million square meters and totaling a length of 955 kilometers. Qingjiang River feeds into the section between Yichang and Zhicheng, which totals a length of around 60.8 kilometers[3]. Zhicheng has a hydrometric station. Jingjiang River has a total length of about 412 kilometers, covering the section between Zhicheng and 
Chenglingji (the outlet of Dongting Lake). The 245 kilometers in the west of Ouchikou is Shangjingjiang River and the section in the east of Ouchikou is Xiajingjiang River. Twists at Zhongzhouzi and Shangchewan were straightened respectively in 1976 and 1969. The twist at Shatanzi was naturally straightened in 1972, witnessing a decrease of more than 70 kilometers in terms of the length. According to the measurement in 1989, Jingjiang River covered a length of about 347.2 kilometers, among which Shangjingjiang River was 171.7 kilometers and Xiajingjiang River was 175.5 kilometers. Dongting Lake is fed by Xiangshui River[4], Zishui river, Ruanshui River, and Lishui River. In addition, it is linked to four outlets of Jingjiang River (Songzi Outlet, Taiping Outlet, Ouchi Outlet, and Tiaoxian Outlet, among which Tiaoxian Outlet has been blocked after establish a tidal gate in 1958). Water and sediment delivered from above sources are impounded in Dongting Lake and then discharged to Yangtze River through Lianhuatang Outlet of Chenglingji. Shashi City and other cities in the lower reach establish gauging and hydrometric stations along Jingjiang River. The section between Zhicheng and Shashi is fed by Juzhang River and discharged through Songzi Outlet and Taiping Outlet. Within the section between Shashi and Chenglingji (Lianhuatang), Xiangshui River, Zishui River, Ruanshui River[5], Lishui River delivers water and sediment from Yangtze River to Dongting Lake through Ouchi Outlet. The section between Chenglingji and Hukou covers a length of 547.0 kilometers. Two hydrometric stations in Lianhuatang and Luoshan controls the water flow from Dongting Lake to Yangtze River. The water flow 3.5 kilometers from Chenglingji to Lianhuatang, 30 kilometers from Lianhuatang to Luoshan, 61 kilometers from Luoshan to Longkou, and 148 kilometers from Longkou to Hankou. Hanshui River (a medium tributary) and Dongjing River (a small tributary) feed into Yangtze River on its north bank. Lushui River and Jinshui River feed into Yangtze River on its south bank[6]. Hanshui hydrometric station controls the outflow of Hanshui River into Yangtze River. The section between Hankou and Hukou totals a length of 284 kilometers, neighboring Daoshui River, Jushui River, Bashui River, Xishui River, and Qishui and other tributaries on its north and adjoining Fushui River, Daye Lake and other tributaries on its south. Poyang Lake feeds into Yangtze River at the lake outlet. Except the gauging station at the outlet, there is also a hydrometric station in Datong in the lower reach of Yangtze River.

\section{Flood Prevention and Regulation Model for the Middle and Lower Reaches of Yangtze River}

In case of no help of the Three Gorges Dam, water flow from Qingjiang River, Xiangshui River, Zishui river, Ruanshui River, and Lishui River, and various tributaries need to processed according to regional division. With reference of the water level of Chenglingji, this research simulates and calculates about two typical floods, so as to verify relationship between lakes and Yangtze River and presetting of relevant parameters. The simulation and calculation could provide detailed and accurate data to later construction of the model[7].

Division of analog computing unit, calculation method, relevant parameters and variable processing technologies are shown in the following parts:

\section{Yichang-Shashi}

With a length of about 146 kilometers, this section is fed by Qingjiang River (Banyuju) on the right bank within the area between Yichang and Shashi. Diverged at Songzi Outlet and Taiping Outlet, this section is fed by Juzhang River.

For major technological processing, this paper takes on-site investigation data of Yichang station as boundary values and also inputs on-site investigation data of Banyuju Station about the tributary Qingjiang river as boundary values. Inflow of the section between Yichang and Shashi 
refers to water flow of Yichang, Banyuju, and Zhicheng. According to analysis, diversion capacity at the two outlets shows significance correlation with total outflow in Shashi (including two flood outlets). The diversion relationship can be presented through plotting or generalization of the diversion ratio. Due to influence of diversion and backwater of the middle and lower reaches, Z-Q relationship of Shashi appears complicated[8]. Parameter relationship curve of Shashi station can be drawn on basis of the water level of Chenglingji. Inflow of the area can be calculated according to the above method. The calculation equation is shown below:

$$
\left\{\begin{array}{l}
Q_{\text {Yi chang }}+Q_{\text {Banyuzui }}+Q_{\text {YiZniSection }}+Q_{\text {uzhanghe }}-Q_{\text {Shashi }}-Q_{\text {SongtaiSection }}=\Delta V / \Delta t \\
V=f_{1}\left(Z_{\text {Shashi }}\right) \\
Q_{\text {Songzi }}=f_{2}\left(Q_{\text {Total }}\right) \\
Q_{\text {Tai pi ng }}=f_{3}\left(Q_{\text {Total }}\right) \\
Q_{\text {Shashi }}=f_{4}\left(Z_{\text {Shashi }}, Z_{\text {Chenglingii }}\right)
\end{array}\right.
$$

Where: $V$ - channel impoundment capacity of corresponding sections, $\Delta V$ - variation values of channel impoundment capacity within the time of $\Delta t, Q$ - the water level, $Z$-water level.

\section{Shashi-Chenglingji}

This section covers a length of about 292 kilometers. It is characterized by complicated water system and interconnecting river network. Except three diversion outlets, this section also enjoys tributaries of four rivers. In addition to influence of this station, the Q-Z relationship of Chengjiling is also subject to influence of backwater of the lower reach, rising water level, and flood diversion etc. According to on-site investigation data about the water level of Chenglingji and the actual water flow of Luoshan station, this paper establishes a curve concerning three parameters of Chenglingji on basis of its rising water level, so as to infer a balance between the water level of Chengling and the outflow of Dongting Lake and Xiajingjiang River. The equation is shown below:

$$
\left\{\begin{array}{l}
I_{1}+I_{2}-Q_{1}+\frac{2 V_{1}}{\Delta t}=Q_{2}+\frac{2 V_{2}}{\Delta t} \\
I=Q_{\text {Shashi }}+Q_{\text {Songtai }}+\sum Q_{\text {sishui }}+Q_{\text {section }} \\
V=f_{1}\left(Z_{\text {Chengli ngji }}, I\right) \\
Q_{\text {Chenglingji }}=f_{2}\left(Z_{\text {Chengli ngji }}, Z_{\text {Vlaterlevel }}\right)
\end{array}\right.
$$

Where: $I$-total inflow of the section, $I_{1}$-total inflow of the previous day, $I_{2}$ - total inflow of the current day, $Q_{1}$ - total outflow of the previous day, $Q_{2}$ - total outflow of the current day.

\section{Flood Routing and Diversion Calculation}

Flood routing and diversion calculation depend on a calculation model of big lakes. According to de Saint-Venant system of equations, this paper integrates data of the rising water level into the water level-water flow curve of Chenglingji, Hankou, and Hukou.

$$
\left\{\frac{d A}{d t}+\frac{d Q}{d x}=0\right.
$$




$$
\frac{d y}{d x}=\frac{1}{g} \times \frac{d u}{d t}+\frac{u}{g} \times \frac{d u}{d x}+\frac{Q^{2}}{K^{2}}
$$

Where: $\mathrm{x}$ - distance,t-flow velocity, $\mathrm{y}$ - water level, $\mathrm{A}$ - flow area, $\mathrm{Q}$ - water flow, $\mathrm{K}$ - flow modulus.

It is necessary to accurately interpret all basic data needed by de Saint-Venant system of equations. This research adopts empirical curve of channel impoundment capacity of hydrology. In certain conditions, this paper will simplify the continuity equation (10) into an equilibrium equation concerning water flow of the section and simplify the dynamic equation (11) into an equation concerning channel impoundment. The simplified equations are shown below:

$$
\left\{\begin{array}{l}
I d t-Q d t=d w \\
W=f(Q, I)
\end{array}\right.
$$

Where: I, Q and W-inflow, outflow and channel impoundment of the section.

The equation (6) can be rewritten according to the channel impoundment as well as the curve concerning the relationship between the water level and water flow on basis of daily rising rate of water level, backwater of the lower reach, and rising water level:

$$
\frac{I_{1}+I_{2}}{2} \times \Delta t-\frac{Q_{1}+Q_{2}}{2} \times \Delta t=W_{2}-W_{1}
$$

Where: $\mathrm{I}_{1}$ and $\mathrm{I}_{2}$ - inflow at the beginning and end of certain period, $\mathrm{Q}_{1}$ and $\mathrm{Q}_{2}$ - outflow during certain period, $\Delta t$ - time (on basis of 1 day), $W_{1}$ and $W_{2}$ - channel impoundment capacity of certain period.

The equation (14) can be rewritten as:

$$
I_{1}+I_{2}-Q_{1}+\frac{2 W_{1}}{\Delta t}=Q_{2}+\frac{2 W_{2}}{\Delta t}
$$

Flood routing calculation gives full consideration to influence of the rising water level according to Flood Routing Calculation of the Main Stream along Middle and Lower Reaches of Yangtze River. In addition, the flood diversion capacity shall be calculated according to the improved calculation model of big lakes. In given conditions, this paper will simplify the continuity equation (10) into an equilibrium equation concerning water flow of the section and simplify the dynamic equation (11) into an equation concerning channel impoundment according to de Saint-Venant system of equations[9]. In addition, this paper researches Yichang-Shashi section, Shashi-Chenglingji section, and Chenglingji-Hankou section according to the channel impoundment as well as the curve concerning the relationship between the water level and water flow on basis of daily rising rate of water level, backwater of the lower reach[10], and rising water level. This paper draws experience from the channel impoundment level stipulated in Basic data (Water Regime) about Flood Prevention along Middle and Lower Reaches of Yangtze River and applied the technological development schedules of the Seventh Five-Year Plan to the section between Hankou and Hukou. This research makes the computation process into a computer program who computation accuracy can be set according to practical demands. This paper inputs 
data about various flow areas and water flows into the database for in-time updating, so as to conclude satisfactory results

Table1: The calculation of flood diversion results

\begin{tabular}{|c|c|c|c|c|c|}
\hline \multirow{2}{*}{$\begin{array}{l}\text { Water level of } \\
\text { station }(\mathrm{m})\end{array}$} & \multirow[t]{2}{*}{ Control station } & \multicolumn{4}{|c|}{$\begin{array}{l}\text { Flood diversion according to control water level of Lianhuatang } \\
\left.\qquad \text { (hundred million } \mathrm{m}^{3}\right)\end{array}$} \\
\hline & & 34.4 & 34.9 & 35.4 & 35.8 \\
\hline \multirow{5}{*}{$\begin{array}{l}\text { Shashi: } 45 \mathrm{~m} \\
\text { Hankou: } 29.5 \mathrm{~m} \\
\text { Hukou: } 22.5 \mathrm{~m}\end{array}$} & Shashi & 13 & 20 & 27.2 & 34.3 \\
\hline & Lianhuatang & 536.2 & 437.7 & 337.9 & 263.9 \\
\hline & Hankou & 6.2 & 17.5 & 49.1 & 82.4 \\
\hline & Hukou & 21.3 & 36.1 & 46.8 & 46.7 \\
\hline & Total & 576.7 & 511.3 & 461 & 427.3 \\
\hline \multirow{5}{*}{$\begin{array}{l}\text { Shashi: } 45 \mathrm{~m} \\
\text { Hankou: } 29.73 \mathrm{~m} \\
\text { Hukou: } 22.5 \mathrm{~m}\end{array}$} & Shashi & 13 & 20 & 27.2 & 34.3 \\
\hline & Lianhuatang & 536.2 & 437.7 & 337.9 & 263.9 \\
\hline & Hankou & 6.2 & 13.6 & 30.8 & 52.9 \\
\hline & Hukou & 21.3 & 40.7 & 61.4 & 61.5 \\
\hline & Total & 576.7 & 512 & 457.3 & 412.6 \\
\hline
\end{tabular}

\section{Calculation and Verification Achievements of Flood Flow}

Except carrying out inspection and statistics on basis of the on-site investigation data of 1998, this paper also adopting the on-site investigation data of 1983, 1998, 2002 and 2015 for verification, just as shown in the following Table:

Table2: Comparison of calculated and observed flood discharge $\left(\mathrm{m}^{3} / \mathrm{s}\right)$

\begin{tabular}{|c|c|c|c|c|c|c|c|}
\hline $\begin{array}{c}\text { Control } \\
\text { station }\end{array}$ & Year & Date & Days & $\begin{array}{l}\text { Average } \\
\text { error }\end{array}$ & $\begin{array}{l}\text { Mean square } \\
\text { error }\end{array}$ & $\begin{array}{c}\text { Maximum } \\
\text { error }\end{array}$ & $\begin{array}{c}\text { Average } \\
\text { arithmetic error }\end{array}$ \\
\hline \multirow{4}{*}{ Shashi } & 1983 & $7.1-8.31$ & 62 & 1415.11 & 1005.4 & 4323 & -232 \\
\cline { 2 - 8 } & 1998 & $5.12-9.21$ & 120 & 1025.30 & 823.9 & 3694 & -112.6 \\
\cline { 2 - 8 } & 2002 & $6.9-9.30$ & 109 & 1134.6 & 698.16 & 2949.9 & 384.8 \\
\cline { 2 - 8 } & 2015 & $7.4-8.20$ & 48 & 803.89 & 652.90 & 2481.20 & 129.09 \\
\hline \multirow{4}{*}{ Lianhuatang } & 1983 & $6.29-7.21$ & 23 & 2428.50 & 1335.18 & 4517.87 & -763.42 \\
\cline { 2 - 8 } & 1998 & $6.8-7.13$ & 36 & 1321.63 & 730.85 & 3595.44 & -448.73 \\
\cline { 2 - 8 } & 2002 & $7.13-8.23$ & 42 & 1618.79 & 918.54 & 3792 & -516.74 \\
\cline { 2 - 8 } & 2015 & $7.1-8.29$ & 60 & 1028.65 & 671.797 & 2804.46 & -662.09 \\
\hline \multirow{5}{*}{ Hankou } & 1983 & $8.27-9.11$ & 16 & 805 & 668.45 & 2335.8 & 643.27 \\
\cline { 2 - 8 } & 1998 & $8.2-9.6$ & 36 & 1006.10 & 676.48 & 2161.8 & 228.87 \\
\cline { 2 - 8 } & 2002 & $8.3-9.28$ & 54 & 1056.01 & 559.53 & 3060 & 351 \\
\cline { 2 - 8 } & 2015 & $7.28-8.19$ & 23 & 502.99 & 249.91 & 943.21 & 42.20 \\
\hline
\end{tabular}

According to Table, it can be found daily average errors of various years vary from 500 $\mathrm{m}^{3} / \mathrm{s}$ to $2400 \mathrm{~m}^{3} / \mathrm{s}$ within a range of $5 \%$. The mean square error varies from $200 \mathrm{~m}^{3} / \mathrm{s}$ to $1700 \mathrm{~m}^{3} / \mathrm{s}$ within a range of $5 \%$. The maximum error of the daily water flow varies from 900 
$\mathrm{m}^{3} / \mathrm{s}$ to $4600 \mathrm{~m}^{3} / \mathrm{s}$. The outcomes are concluded on basis of the data of 935 days. Most of the outcomes show a variation range of less than $6 \%$. The average arithmetical error stays below 800 $\mathrm{m}^{3} / \mathrm{s}$ within a range of less than $2 \%$. This indicates the calculation of water flow achieves high precision standard.

\section{Conclusion}

This research adopts on-site investigation data collected from the end of last century and the beginning of this century, namely daily average water level and water flow during the flooding period of the middle and lower reaches of Yangtze River over the period from 1981 to 2015. Whatever Yangtze River changes, the data about its water level and water flow can be updated in response to the changes. Therefore, we can take practical and reasonable measures by gaining better understanding about actual conditions of the dynamic river changes. Except proposing improvement of the calculation model of big lakes, this paper also carries out practical simulation about typical floods by taking the water level of Chenglingji as the control standard, so as to verify relevant parameters of relationships between lakes the Yangtze River and provide detailed and accurate information for construction of subsequent models. By comparison with on-site investigation data, it can be found the calculation outcomes have achieved high precisions standard. This system can be used in flood forecast and prevention of Yangtze River, because it can facilitate the rational decision-making about the flood prevention.

\section{References}

[1] WAN Feng-ming, LONG Li-hua, ZHANG Yue.Single Valued Processing of Stage-Discharge Relation in the Main Cross Section of Middle Reaches of Yangtze River[J].Journal of Yangtze River Scientific Research Institute.2012,29(12):5-9

[2] Zou bingyu, Li Shiqiang, Applicability of Single-valied Lake Routing Model at the Luoshan Station[J].Journal of china hydrology.2011,S1:140-142

[3] Shi Yong, Luan Zhenyu, Chen liangang.Numerical study on the evolution trend in the river-lake relationship in the middle and lower reaches of the Yangtze River[J].Advances in Water Science,2010(11)

[4] ZHANG Yan-xia,ZHANG Xiao-feng, YANG Fang-li.Integrated Mathematical Model Research of Flood Routing for the Hanjiang River and the Yangtze River[J].China Rural Water and Hydropower.2008,6:32-34

[5] XIE Zuo-tao, ZHANG Xiao-feng, TAN Guang-ming, YANG Fang-li.Study and application of mathematical model for one-dimensional flood-routing[J].Engineering Journal of Wuhan University.2005,1:69-72

[6]Zhong Zi-yu, Xu Cheng-long, Hu Wei-zong. Hydrologic Flood Routing Model for the Middle and Liwer Yangtze River [J].Advances in water science.1996,7(4):354-360

[7] Zhang Youxing, Liu Xiaoqun, Lu xiang. Flood simulation in the middle and downstream reaches of the Yangtze River[J].Water Resources and Hydropower of Human, 2003(5)

[8]MU Jinbin, Zhang Xiaofeng, Bai Yang, Chen Jian. A flood routing model for Jingjiang River-Dongting Lake and its application[J]. Engineering Journal of Wuhan University.2009,1: 96-100

[9] Tian Xuemin, Xie Jiancang. Flood Routing Model in the Flood Control System and its 
Application[J].Journal of Water Resources\& Water Engineering,2009,20:60-66

[10] Li Daming, Guan Yongkuan, Li Lingling,etc.Flood routing mathematical model for flood detention basin[J]. Hudro-science And Engineering,2011,9:27-35 